\title{
BMJ Open Effects of five types of selenium supplementation for treatment of Kashin-Beck disease in children: a systematic review and network meta- analysis
}

\author{
Dongmei Xie, ${ }^{1,2}$ Yulin Liao, ${ }^{2}$ Jirong Yue, ${ }^{1,2}$ Chao Zhang, ${ }^{3}$ Yanyan Wang, ${ }^{2}$ \\ Chuanyao Deng, ${ }^{2}$ Ling Chen ${ }^{2}$
}

To cite: Xie D, Liao Y, Yue J, et al. Effects of five types of selenium supplementation for treatment of KashinBeck disease in children: a systematic review and network meta-analysis. BMJ Open 2018;8:e017883. doi:10.1136/ bmjopen-2017-017883

- Prepublication history and additional material for this paper are available online. To view these files, please visit the journal online (http://dx.doi. org/10.1136/bmjopen-2017017883).

Received 22 May 2017 Revised 16 January 2018 Accepted 22 January 2018

Check for updates

${ }^{1}$ National Clinical Research Center for Geriatrics, West China Hospital, Sichuan University ${ }^{2}$ Department of Geriatrics, West China Hospital, Sichuan University, Chengdu, China ${ }^{3}$ Center for Evidence-based Medicine and Clinical Research, Taine Hospital, Hubei University of Medicine, Shiyan, China

Correspondence to

Dr Jirong Yue;

yuejirong11@hotmail.com

\section{ABSTRACT}

Objective To compare the effectiveness of five kinds of selenium supplementation for the treatment of patients with Kashin-Beck disease, and rank these selenium supplementations based on their performance.

Design We searched for all publications between 1 January 1966 and 31 March 2017 using seven electronic databases. GRADE system to network meta-analyses (NMAs) was applied to rate the quality of the evidence. We conducted a random effects model NMA in STATA 12.1 to determine comparative effectiveness of each intervention. Rankings were obtained by using the surface under the cumulative ranking curve (SUCRA) values and mean ranks. Results A total of 15 randomised controlled trials involving 2931 patients were included. After assessment of the overall quality of the evidence, we downgraded our primary outcomes from high to low or very low quality. NMAs showed that all five kinds of selenium supplementation had higher metaphysis X-ray improvement which were superior to placebo. Ranking on efficacy indicated that selenium salt was ranked the highest, followed by sodium selenite + vitamin E, selenium enriched yeast, sodium selenite and then sodium selenite + vitamin C.

Conclusions Based on the results of NMA, all five types of selenium supplements are more effective than placebo and so that selenium supplementation is of help in repairing metaphyseal lesions. Since the overall quality of the evidence was low or very low, the SUCRA values may be misleading and should be considered jointly with the The Grading of Recommendations Assessment, Development and Evaluation (GRADE) confidence in the estimates for each comparison. The quality of the evidence is insufficient to draw a conclusion about what method of selenium supplementation is most effective.

PROSPERO registration number CRD42016051874.

\section{INTRODUCTION}

Kashin-Beck disease (KBD) is an endemic, chronic, disabling degenerative disorder of peripheral joints and spine. ${ }^{12}$ It is present primarily among people in southeast Siberia,
Strengths and limitations of this study

- The present network meta-analysis (NMA) integrated evidence from direct and indirect comparisons. We applied GRADE system to NMA-based GRADE working group to rate the quality of the evidence.

- We comprehensively summarised all randomisedcontrolled trials (RCTs) of selenium supplements for Kashin-Beck disease.

- Despite our exhaustive search, only 15 RCTs conducted in China were included in this review. Some trials may have been published in local journals that were missed in our search.

- The overall quality of the evidence was low or very low. The surface under the cumulative ranking curve values may be misleading and should be considered jointly with the GRADE confidence in the estimates for each comparison.

north Korea and China. ${ }^{3}$ KBD is prevalent in 377 counties of 14 provinces in China, with 0.64 million cases. ${ }^{4} \mathrm{KBD}$ occurs in childhood and includes alterations in the epiphysial plate and metaphysis. This leads to a variety of complications, such as bony deformity, joints enlargement, growth retardation and functional impairment in multiple joints, which is a significant human and social economically problem for all individuals involved. Moreover, KBD can also cause disruptive cartilage metabolism lipid peroxidation, and disturb the metabolism of selenium and sulfur. ${ }^{56}$ Because of the incomplete ability of the cartilage to repair itself, only few therapies are available to treat KBD. For example, non-steroidal anti-inflammatory drugs, ${ }^{7}$ sodium hyaluronate, ${ }^{8}$ physical therapy ${ }^{9}$ and chondroitin sulfate combined with glucosamine are an option. ${ }^{10}$ Moreover, orthopaedists have demonstrated that surgery to repair joint defects is beneficial. ${ }^{11} 12$ 
Although the aetiology of KBD is multifactorial, one of the major environmental risk factors is selenium deficiency. ${ }^{13}$ Since the 1970 s, selenium was administered in several severely endemic regions. A meta-analysis study consisting of 5 randomised-controlled trials (RCTs) as well as 10 non-RCTs demonstrated benefits of selenium administration in preventing KBD in children. ${ }^{14}$ Another systematic review suggested that sodium selenite (Se) was effective for the treatment of patients already affected with KBD. ${ }^{15}$ Besides Se tablet, there are other selenium supplements used for treating KBD, including selenium salts (Se salt), selenium enriched yeast (Se yeast), combining sodium selenite and vitamin $\mathrm{E}(\mathrm{Se}+\mathrm{VE})$ and combining sodium selenite and vitamin $\mathrm{C}(\mathrm{Se}+\mathrm{VC})$. At the time of our review, there were few head-to-head comparisons of different types of selenium supplement for treatment of KBD. In light of the need for government policy-makers and clinical care workers to know the effects of a set of alternative options, a systematic review and network meta-analysis (NMA) was performed. This study aimed at comparing the effectiveness of administration of selenium in treating patients with $\mathrm{KBD}$, and rank these selenium supplementations based on their performance.

\section{METHOD}

In this study, a protocol was devised according to PRISMA (Preferred Reporting Items for Systematic Reviews and Meta-Analyses) guidelines. The protocol was registered on International prospective register of systematic reviews (PROSPERO), and the trial registration number was CRD42016051874.

\section{Search strategy}

We searched all the literature from 1 January 1966 to 31 March 2017. In our study, we used electronic databases, including EMBASE, MEDLINE, The Cochrane Database of Systematic Reviews, The Cochrane Central Register of Controlled Trials, The Chinese Biomedical Database, Chinese National Knowledge Infrastructure, Chinese Science and Technique Journals Database, and the Wan Fang database. Keywords used in our search criteria included KBD, big bone disease, Urov disease, endemic osteoarthritis, as well as selenium, sodium selenite and Se. Online supplementary appendix box 1 presents the Ovid search strategy used. For identification of additional studies of interest, references from publications were manually screened.

\section{Eligibility criteria}

We included all RCTs that used Se tablet and other types of selenium supplements including Se salt, Se yeast, $\mathrm{Se}+\mathrm{VE}$ and $\mathrm{Se}+\mathrm{VC}$ for patients with KBD. The control groups included placebo or no treatment controls, or other active medicines. The diagnostic criteria used for KBD was based on the Diagnosis Criteria for Kashin-Beck Disease (GB16003-1995), which was developed by the National Health and Family Planning Commission of China. ${ }^{16}$ We excluded the following studies: (1) studies with small sample sizes (numbers of patients $<20$ in each treatment group); (2) preventive studies; (3) studies without available information of interest. The studies in which individuals with and without KBD were enrolled only if the therapeutic effect data could be extracted. Outcome of interest to this review was the rate of repair of metaphyseal lesions using X-ray film. Typically, repair was defined as being cured basically or improved significantly of metaphyseal lesions according to the latest judgement standard of X-ray for treatment effect of KBD. ${ }^{17}$

\section{Data extraction and quality evaluation}

Two authors (YL and DX) independently screened all citations identified by the searches. Full-text articles of potential studies were obtained and assessed according to the aforementioned inclusion criteria. The data extraction form included publication (first author, year of publication), demographics (sample size and age), interventions (dose, administration route and length of therapy), the follow-up period and outcomes. To determine the overall OR, data were extracted to the closest 12 months because this time point was reported in all included RCTs. Two reviewers independently evaluated the methodological quality of individual study according to the Cochrane risk-of-bias tool. ${ }^{18}$ In our review, we applied the GRADE system to our NMA based on the GRADE working group. ${ }^{19}$ The methods of rating the quality of direct comparison are the same for GRADE in traditional meta-analysis. Evidence was downgraded by one level from 'high quality' for significant (or by two levels for very significant), study limitations (risk of bias), indirect of evidence, inconsistency, imprecision of effects or potential bias in publication. The rating of quality of indirect estimates was based on the ratings of the two pairwise estimates that contributes to the indirect estimate of the comparison of interest. The lower rating score of direct comparisons comprises the confidence score of indirect comparisons. When direct and indirect evidences were available, the highest score was used as a quality score for NMA assessment. ${ }^{19}$ In addition, we needed to consider the intransitivity among different groups and the inconsistency between direct comparison and indirect comparison. Furthermore, we used the GRADE profiler to help us create 'Summary of findings' tables. In case of a discrepancy, an additional experienced rater was consulted (JY).

\section{Statistical analysis}

As the repair rate of metaphyseal lesions on X-ray film, the outcome of interest in this text, was a discontinuous statistics, we calculated the OR and its 95\% CI as the effect estimates. The reason why ORs were used instead of risk ratios (RRs) was as follows: the inferential fallacies by using RR in indirect comparison offers the possibility for abuse regarding choice when outlining outcomes and confound the decision-making process in which both 


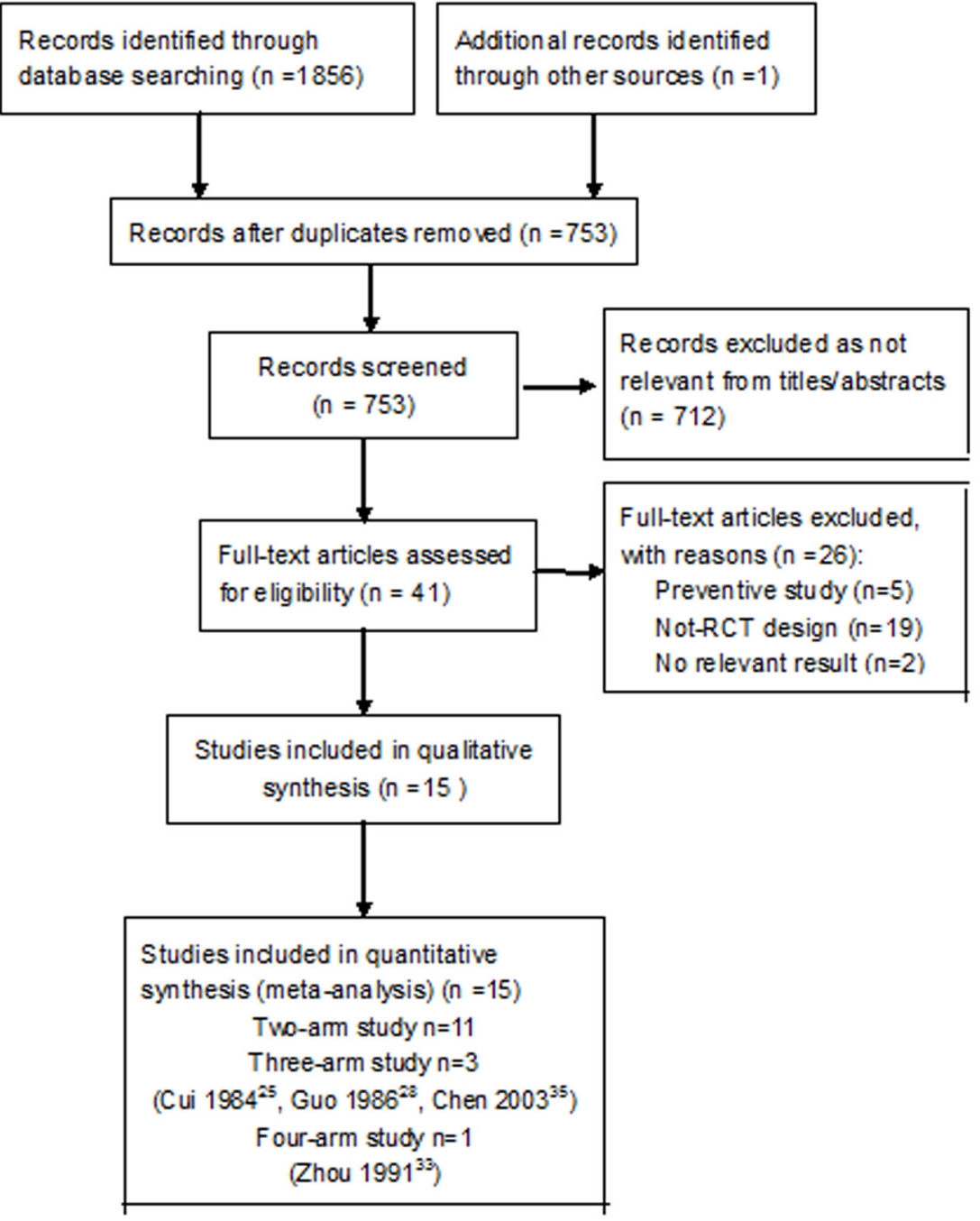

Figure 1 Flow diagram of included study. RCT, randomised-controlled trial.

data sets are shown. ORs can overcome this misconception, and dependably interprets regarding treatment effect direction in indirect comparisons. ${ }^{20}$ Initially, we performed standard pairwise meta-analyses for all available direct comparisons using a random effects model in RevMan V.5.3. Statistical heterogeneity of treatment effects across studies was assessed by the Cochrane $Q$ test, and the extent of between-study heterogeneity was quantified by $\mathrm{I}^{2}$, which with a value $>50 \%$ indicates significant heterogeneity. Then, to estimate the efficiency of each intervention, a random effects model NMA was performed in STATA by conducting a network command and self-programmed STATA, which can be found at http://www.mtm.uoi.gr. We present the mean effect sizes for the network estimates (OR) along with their 95\% CI and prediction intervals (PrI). The PrI shows the predicted parameter around estimated treatment effects in the future study.
To evaluate consistency within a network, a 'design-bytreatment' model was used, as performed by Higgins $e t$ $a l^{18}$, by using the network meta command in STATA. This approach accounted for several causes of inconsistency, which may have occurred when studies with different designs (two-arm trials vs three-arm trials) give different results as well as disagreement between direct and indirect evidences. ${ }^{21}$ In this study, the $X^{2}$ test was used to determine any inconsistency within the network, and $\mathrm{P}>0.05$ indicated that the direct and indirect comparisons within the network were consistent.

We also estimated the ranking probabilities for all treatment methods at each possible rank. Rankings were obtained by the surface under the cumulative ranking curve (SUCRA) values as well as mean ranks. SUCRA could be presented as a percentage of effectiveness of a treatment method that would be ranked first without hesitation. To derive these SUCRA values, 


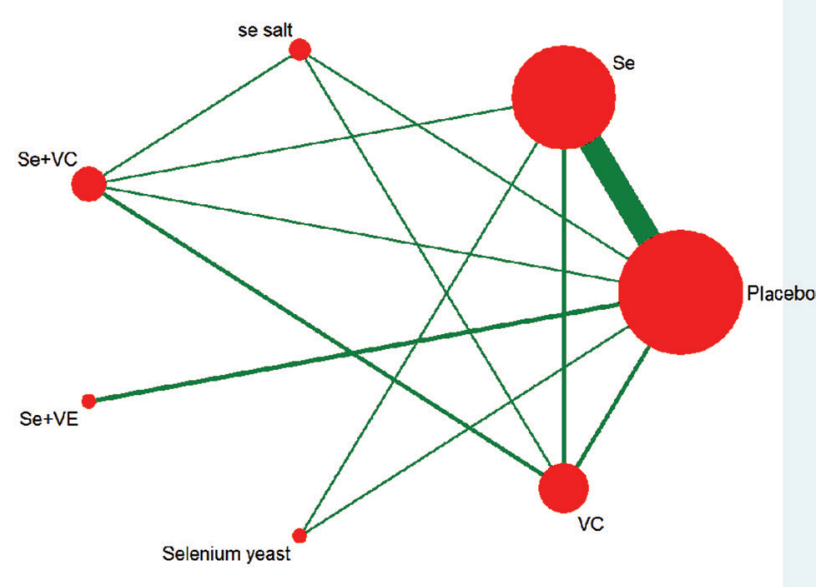

Figure 2 Network of eligible comparisons for treatment efficacy network meta-analysis for Kashin-Beck disease. The width of lines is proportional to the number of studies compared in every pair of treatments, and the size of nodes is proportional to the total sample size of each treatment. Two-arm study, $n=11$; three-arm study, $n=3$ (Cui 1984, ${ }^{25}$ Guo 1986, ${ }^{28}$ Chen $2003^{35}$ ); four-arm study, $\mathrm{n}=1$ (Zhou 1991 ${ }^{31}$ ) Se, sodium selenite; Se salt, selenium salt; Se+VC, the combination of sodium selenite with vitamin C; Se+VE, the combination of sodium selenite with vitamin E; SE yeast, selenium enriched yeast; VC, vitamin C .

we used the ranking probabilities estimated from the mvmeta command.

\section{RESULTS}

\section{Study inclusion and characteristics}

Initial searches yielded 1857 citations. Of these, 1816 duplicate or irrelevant records were excluded and fulltext articles of the remaining 41 studies were retrieved for further assessment according to the inclusion criteria. A total of 15 studies $^{22-36}$ containing 2931 patient were included eventually in our meta-analysis (figure 1). We excluded 26 trials for the reasons documented in the characteristics of excluded studies table (online supplementary appendix table 1 ).

A total of seven interventions were evaluated: Se, Se salt, Se yeast, Se+VE, Se+VC, VC and placebo. Figure 2 shows the network of all treatment comparisons included in this review. The age of participants ranges from 2 to 16 years, and the duration of follow-up varied from 6 to 36 months. The main characteristics of the included studies were similar, and the characteristics (eg, interventions dosage, route of administration, duration of treatment, the follow-up period and outcomes) are presented in online supplementary appendix table 2 .

\section{Overall assessment for evidence quality}

All included trials were reported to be RCTs. The quality of included studies was overall low. Study quality for each study can be seen in online supplementary appendix table 3. We downgraded this outcome from high to low or
Table 1 Quality ratings for comparison of different interventions

\begin{tabular}{|c|c|c|c|}
\hline Comparison & $\begin{array}{l}\text { Quality } \\
\text { of direct } \\
\text { evidence }\end{array}$ & $\begin{array}{l}\text { Quality of } \\
\text { indirect } \\
\text { evidence }\end{array}$ & $\begin{array}{l}\text { Quality of } \\
\text { network } \\
\text { meta-analysis } \\
\text { evidence }\end{array}$ \\
\hline Se vs placebo & Low $^{*} \dagger$ & Low* $^{*}$ & Low $^{*} \dagger$ \\
\hline $\begin{array}{l}\text { Se salt vs } \\
\text { placebo }\end{array}$ & $\operatorname{Low}^{*} \dagger$ & $\operatorname{Low}^{*} \ddagger$ & Low $^{*} \dagger$ \\
\hline $\begin{array}{l}\text { Se+VCvs } \\
\text { placebo }\end{array}$ & Moderate* & Low $^{\star} \ddagger$ & Moderate* \\
\hline $\begin{array}{l}\text { Se+VEvs } \\
\text { placebo }\end{array}$ & Very low* $† \S$ & Low $^{\star} \ddagger$ & Low $^{*} \ddagger$ \\
\hline $\begin{array}{l}\text { Se yeast vs } \\
\text { placebo }\end{array}$ & Moderate* & Low $^{*} \ddagger$ & Moderate* \\
\hline VC vs placebo & Moderate* & Low $^{*} \ddagger$ & Moderate* \\
\hline Se salt vs Se & - & Very low§ી & Very low^§l \\
\hline $\mathrm{Se}+\mathrm{VC}$ vs Se & Moderate* & $\operatorname{Low}^{\star} \S$ & Moderate* \\
\hline $\mathrm{Se}+$ VEvs Se & - & Very low§ી & Very low§ી \\
\hline Se yeast vs Se & Moderate* & Very low§ી & Moderate* \\
\hline VC vs Se & Moderate* & Low*ף & Moderate* \\
\hline Se+VC vs Se salt & $\operatorname{Low}^{\star} \ddagger$ & Low*q & Low*q \\
\hline Se+VEvs Se salt & - & Very low§ף & Very low§】 \\
\hline $\begin{array}{l}\text { Se yeast vs Se } \\
\text { salt }\end{array}$ & - & Very low§ף & Very low§ી \\
\hline VC vs Se salt & $\operatorname{Low}^{\star} \S$ & Very low§ી & Low*, \\
\hline $\mathrm{Se}+\mathrm{VE}$ vs Se+VC & - & Very low§ף & Very low§ી \\
\hline $\begin{array}{l}\text { Se yeast vs } \\
\text { Se+VC }\end{array}$ & - & Very low§ી & Very low§ી \\
\hline VC vs Se+VC & Moderate* & Very low§ી & Moderate* $^{\star}$ \\
\hline $\begin{array}{l}\text { Se yeast vs } \\
\text { Se+VE }\end{array}$ & - & Very low§ી & Very low§ી \\
\hline VC vs Se+VE & - & Very low§ף & Very low§』 \\
\hline VC vs Se yeast & - & Very low§ી & Very low§ી \\
\hline
\end{tabular}

*Limitations (risk of bias).

†Inconsistency.

łInconsistency for indirect evidence: prediction intervals for treatment effect include effects that would have different interpretations.

IIndirectness: no convincing evidence for the plausibility of the transitivity assumption.

§Imprecision.

Se, sodium selenite; Se salt, selenium salt; $\mathrm{Se}+\mathrm{VC}$, the combination of sodium selenite with vitamin C; Se+VE, the combination of sodium selenite with vitamin $\mathrm{E}$; $\mathrm{Se}$ yeast, selenium enriched yeast; VC, vitamin C.

very low quality for possible bias, inconsistency or imprecision. Overall assessment for evidence quality was seen in table 1.

\section{Intervention-control pairwise meta-analyses}

All RCTs reported repair rate of metaphyseal lesions on $\mathrm{X}$-ray films. The individual study data used in the analyses were listed in online supplementary appendix table 
Table 2 Summary of findings for each intervention in comparison to placebo

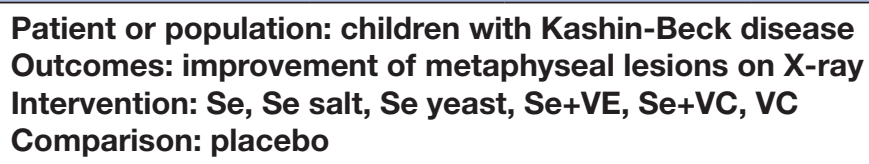

\begin{tabular}{|c|c|c|c|c|c|c|}
\hline \multirow[b]{2}{*}{$\begin{array}{l}\text { Intervention/ } \\
\text { comparison }\end{array}$} & \multicolumn{2}{|c|}{$\begin{array}{l}\text { Anticipated absolute } \\
\text { effects* }(95 \% \mathrm{Cl})\end{array}$} & \multirow{2}{*}{$\begin{array}{l}\text { Relative effect } \\
(95 \% \mathrm{Cl}) \text { (based } \\
\text { on network meta- } \\
\text { analysis) }\end{array}$} & \multirow{2}{*}{ SUCRA } & \multirow[b]{2}{*}{$\begin{array}{l}\text { No. of participants } \\
\text { (studies with } \\
\text { direct evidence) }\end{array}$} & \multirow{2}{*}{$\begin{array}{l}\text { Quality of the } \\
\text { evidence based } \\
\text { on network meta- } \\
\text { analysis } \\
\text { (GRADE) }\end{array}$} \\
\hline & $\begin{array}{l}\text { Repair } \\
\text { rate with } \\
\text { placebo }\end{array}$ & $\begin{array}{l}\text { Repair rate } \\
\text { with Se }\end{array}$ & & & & \\
\hline Se salt vs placebo & 34 per 100 & $\begin{array}{l}87 \text { per } 100 \\
(60 \text { to } 97)\end{array}$ & $\begin{array}{l}\text { OR } 12.37 \\
\text { (2.81 to } 54.41)\end{array}$ & $86.0 \%$ & $\begin{array}{l}59 \\
(1 \mathrm{RCT})\end{array}$ & $\begin{array}{l}\oplus \oplus \bigcirc \bigcirc \\
\text { Low †‡ }\end{array}$ \\
\hline Se yeast vs placebo & 38 per 100 & $\begin{array}{l}78 \text { per } 100 \\
\text { (51 to } 93)\end{array}$ & $\begin{array}{l}\text { OR } 5.81 \\
\text { (1.70 to } 19.89)\end{array}$ & $62.5 \%$ & $\begin{array}{l}120 \\
(1 \mathrm{RCT})\end{array}$ & $\begin{array}{l}\oplus \oplus \oplus \bigcirc \\
\text { Moderate }\end{array}$ \\
\hline Se vs placebo & 42 per 100 & $\begin{array}{l}77 \text { per } 100 \\
(69 \text { to } 84)\end{array}$ & $\begin{array}{l}\text { OR } 4.68 \\
\text { (2.99 to } 7.34)\end{array}$ & $52.5 \%$ & $\begin{array}{l}2427 \\
\text { (11 RCTs) }\end{array}$ & $\begin{array}{l}\oplus \oplus \bigcirc \bigcirc \\
\text { Low } \$ \S\end{array}$ \\
\hline
\end{tabular}

GRADE Working Group grades of evidence.

High quality: we are very confident that the true effect lies close to that of the estimate of the effect.

Moderate quality: we are moderately confident in the effect estimate. The true effect is likely to be close to the estimate of the effect, but there is a possibility that it is substantially different.

Low quality: our confidence in the effect estimate is limited. The true effect may be substantially different from the estimate of the effect. Very low quality: we have very little confidence in the effect estimate. The true effect is likely to be substantially different from the estimate of effect.

${ }^{*}$ The repair rate in the intervention group (and its $95 \% \mathrm{Cl}$ ) is based on the assumed rate in the comparison group and the relative effect of the intervention (and its $95 \% \mathrm{Cl}$ ).

†Limitations (risk of bias): no studies described adequate methods regarding the sequence of randomisation and reported allocation concealment. Some studies did not use of a blinding method and intention-to-treat analysis.

‡lnconsistency: small sample size ora higher $\mathrm{I}^{2}$ or both.

§Imprecision: the effects are large but the overall sample size is low.

$\mathrm{RCT}$, randomised-controlled trial; Se, sodium selenite; Se salt, selenium salt; Se+VC, the combination of sodium selenite with vitamin C;

$\mathrm{Se}+\mathrm{VE}$, the combination of sodium selenite with vitamin E, Se yeast, selenium enriched yeast; SUCRA, surface under the cumulative ranking curve; VC, vitamin C.

4. Follow-up duration of included RCTs was varied. We extracted data to the nearest 12 months to estimate the overall OR. When compared with placebo, the pooled OR (random effects model) of X-ray improvement was in favour of Se (OR 5.0, 95\% CI 3.21 to 7.78, $\left.\mathrm{P}<0.001, \mathrm{I}^{2}=70 \%\right)$, Se salt (OR $7.6,95 \%$ CI 2.34 to 24.67 , $\mathrm{P}=0.001$ ), Se enriched yeast (OR $3.75,95 \%$ CI 1.76 to 8.02, $\mathrm{P}=0.001$ ) and $\mathrm{Se}+\mathrm{VE}$ (OR $11.05,95 \%$ CI 2.61 to $\left.46.80, \mathrm{P}=0.03, \mathrm{I}^{2}=60 \%\right)$, respectively, which indicated that repairing rate of metaphyseal lesions on X-ray films was significantly higher for these drugs than that for placebo (see online supplementary appendix figure). Summary of findings for each selenium supplement compared with placebo was seen in table 2. A few RCTs reported direct comparisons among active interventions. There were two RCTs that compared Se with VC; the pooled OR of two RCTs also showed that no significant difference exists (OR 1.15, 95\% CI 0.51 to 2.63, $\left.\mathrm{P}=0.93, \mathrm{I}^{2}=0 \%\right) .{ }^{2535}$ There was only one RCT for Se vs
Se yeast, ${ }^{28}$ Se vs $\mathrm{Se}+\mathrm{VC},{ }^{33}$ Se salt vs $\mathrm{Se}+\mathrm{VC},{ }^{33}$ Se salt vs $\mathrm{VC},{ }^{33}$ respectively. OR of X-ray improvement was significantly higher in Se salt group compared with $\mathrm{Se}+\mathrm{VC}$ (OR 6.00, 95\% CI 1.81 to $19.93, \mathrm{P}=0.003$ ) and $\mathrm{VC}$ alone (OR 4.24, 95\% CI 1.39 to $12.90, \mathrm{P}=0.011$ ). There were no significant differences noted in other active intervention comparisons (see table 3 ).

\section{Results of NMAs and consistency test}

The pooled OR and 95\% CI of X-ray improvement for active treatment compared with placebo was 4.68 (2.99 to 7.34) for Se, 12.37 (2.81 to 54.41) for Se salt, 5.81 (1.70 to 19.89 ) for Se enriched yeast, 10.72 (3.14 to 36.57) for $\mathrm{Se}+\mathrm{VE}$ and 3.26 (1.14 to 9.28) for $\mathrm{Se}+\mathrm{VC}$, respectively, which indicated a significant difference in efficacy. For the comparison between active treatments, no significant differences were found. More details were presented in table 3. In figure 3, we presented the OR for the network estimates along with 95\% CI and PrI. 
Table 3 Results of pairwise and network meta-analyses of repairing rate of metaphyseal lesions on X-ray films

\begin{tabular}{|c|c|c|c|c|c|c|}
\hline $\begin{array}{l}\text { OR } \\
(95 \% \mathrm{Cl}) \text { * }\end{array}$ & Placebo & $\mathrm{Se}$ & Se salt & $\mathrm{Se}+\mathrm{VC}$ & $\mathrm{Se}+\mathrm{VE}$ & Se yeast \\
\hline $\mathrm{Se}$ & $\begin{array}{l}4.68(2.99 \text { to } 7.34)^{\star} \\
5.00(3.21 \text { to } 7.78)\end{array}$ & - & - & - & - & - \\
\hline Se salt & $\begin{array}{l}12.37(2.81 \text { to } 54.41)^{\star} \\
7.60(2.34 \text { to } 24.67)\end{array}$ & $\begin{array}{l}2.64(0.59 \text { to } 11.84) \\
-\end{array}$ & - & - & - & - \\
\hline $\mathrm{Se}+\mathrm{VC}$ & $\begin{array}{l}3.26(1.14 \text { to } 9.28)^{*} \\
1.27(0.42 \text { to } 3.83)\end{array}$ & $\begin{array}{l}0.70(0.25 \text { to } 1.97) \\
1.30(0.57 \text { to } 2.94)\end{array}$ & $\begin{array}{l}0.26(0.06 \text { to } 1.20) \\
0.17(0.05 \text { to } 0.55)\end{array}$ & - & - & - \\
\hline $\mathrm{Se}+\mathrm{VE}$ & $\begin{array}{l}10.72(3.14 \text { to } 36.57)^{\star} \\
11.05 \text { (2.61 to } 46.80)\end{array}$ & $\begin{array}{l}2.29 \text { (0.62 to } 8.43) \\
-\end{array}$ & $\begin{array}{l}0.87 \text { (0.13 to } 5.93) \\
-\end{array}$ & $\begin{array}{l}3.29 \text { (0.65 to } 16.53) \\
-\end{array}$ & - & - \\
\hline Se yeast & $\begin{array}{l}5.81(1.70 \text { to } 19.89)^{*} \\
3.75(1.76 \text { to } 8.02)\end{array}$ & $\begin{array}{l}1.24(0.36 \text { to } 4.25) \\
1.92(0.90 \text { to } 4.00)\end{array}$ & $\begin{array}{l}0.47 \text { (0.07 to } 3.16) \\
-\end{array}$ & $\begin{array}{l}1.78(0.37 \text { to } 8.66) \\
-\end{array}$ & $\begin{array}{l}0.54(0.10 \\
\text { to } 3.08) \\
-\end{array}$ & - \\
\hline
\end{tabular}

In each cell, the first line represents the result of network meta-analyses, and the second row represents the result of pairwise meta-analyses. ${ }^{*}$ ORs represent odds of repair in row treatment versus column treatment. ORs larger than 1 denote higher repair rate in row treatment than column treatment.

Se, sodium selenite; Se salt, selenium salt; Se+VC, the combination of sodium selenite with vitamin C; Se+VE, the combination of sodium selenite with vitamin E; Se yeast, selenium enriched yeast; VC, vitamin C.

There was no inconsistency between direct and indirect evidences according to the design-by-treatment interaction model $(\mathrm{P}=0.88)$, implying that direct and indirect evidences were mainly consistent (figure 4 ). However, the results of the comparison of Se+VCand VC versus placebo showed some degree of inconsistency. Actually, the lower CI for X-ray improvement was nearly equal to 1 (1.13 for Se+VCand 1.27 for VC), showing a trend to coincide with direct results.

Table 2 and figure 5 displayed the distribution of probabilities for each treatment being ranked for their efficacy in KBD according to the SUCRA values.

\section{DISCUSSION}

\section{Principal findings}

Our NMA of all 15 available RCTs in 2931 patients with KBD showed that all five kinds of selenium supplementation (including Se, Se salt, Se enriched yeast, Se+VE, $\mathrm{Se}+\mathrm{VC}$ ) were superior to placebo/no treatment in repairing metaphyseal lesions. There was uncertainty around the difference between two active treatments. However, the probabilistic ranking of interventions showed that Se salt was ranked the most effective, followed by $\mathrm{Se}+\mathrm{VE}$, Se enriched yeast, Se and then $\mathrm{Se}+\mathrm{VC}$.

\section{Relation to other studies}

Studies have proposed that a deficiency in selenium is key in disposing target cells, such as chondrocytes, to oxidative stress. ${ }^{37}$ In most highly endemic area, the level of total soil selenium concentrations is typically low. In a previous study, it was demonstrated that in endemic regions, selenium concentrations in water, soil, cereal and corn were reduced compared with regions without high rates of KBD ${ }^{38}$ Furthermore, the majority of individuals who live in areas with $\mathrm{KBD}$ have a low selenium nutritive status, as is indicated by the low levels of selenium in their serum, red blood cell, urine and hair.

The effectiveness of various methods of selenium supplementation for children has been demonstrated by many studies including Se salt, ${ }^{39}$ Se enriched yeast, ${ }^{28}$ oral sodium selenite tablet, ${ }^{17}$ spraying Se on $\operatorname{crops}^{40}$ and Se enriched fertiliser. ${ }^{41}$ Selenium supplementation was related to a reduced $\mathrm{KBD}$ prevalence, along with an increased selenium content in the hair of individuals who live in areas with KBD. It was reported that the incidence of radiographic evidence of metaphysical lesions of the hands was $44.8 \%$ in 1990 at Cuimu town of the Shaanxi province in children aged 7-12years. After implementation of comprehensive prevention measures of KBD, especially using Se salt, the incidence these X-ray findings decreased to $0.3 \%$ in $2010 .{ }^{42}$ The low incidence of KBD also may explain why there has not been any studies about Se treatment for KBD published in recent years.

Se salt was produced as follows: a total of $0.833 \mathrm{~g}$ sodium selenite powder was added to $50 \mathrm{~kg}$ source salt and expanded to 1:60 000 of Se salt. Although administration of Se tablet is effective for prevention and treatment of KBD in children, ${ }^{16}{ }^{17}$ it is very difficult for many children who reside in endemic areas to adhere to any type of long-term medication. However, salt is a necessary part of daily life and food intake. The compliance can be more effectively guaranteed. A limitation to the findings about Se salt is that due to the difficulty of carrying out a RCT comparing Se salt with placebo or other active drugs, only one RCT has been done. ${ }^{33}$ However, one meta-analysis involving 11 non-RCTs (2652 participants) also showed that supplement Se salt was effective for preventing and treatment for KBD in children. ${ }^{39}$ Since Se salt is the most economical way for low-income families, it is anticipated 
that continuous use of Se salt and other comprehensive prevention approaches could be beneficial in eliminating KBD cartilage damages in children. ${ }^{43}$

Despite the evidence in our meta-analysis, there remains some controversy around selenium supplementation in relationship with iodine deficiency. In a previous study that was performed in the Tibet area, Moreno-Reyes et al did not find a relation between KBD ad selenium deficiency, whereas they did identify iodine deficiency as a risk factor. ${ }^{44}$ Similarly, the only RCT $^{34}$ published in English in our review showed only one case of improvements in $\mathrm{X}$-ray in sodium selenite group. The above studies should, however, be interpreted with caution. These studies were all performed in the Tibet area where selenium and iodine are both deficient in the diet. Moreover, both selenium and iodine deficiency are risk factors of KBD. ${ }^{37}$ Previous studies have shown growth retardation in rats that were fed a diet containing low selenium levels. ${ }^{45}$ In addition, impaired development of the bone was demonstrated when rats were fed a iodine-deficient diet. ${ }^{46}$ Supplementation with selenium may not counterbalance the negative effects of long-term iodine deficiency. Thus, it does not seem very likely that KBD has only one cause.
Additional factors (both genetic and environmental) may be a protective or show disease acceleration.

\section{Methodological quality of included trials}

Overall, the methodological quality of the included trails was low. In all the included trials, methods of randomisation and allocation concealment were not presented. In eight trials, double blinding was described, whereas specifics of the methods of blinding were described in three trials. Withdrawal rates of participants were $<20 \%$ in eight trails. Only six trials performed intention-to-treat analysis.

After evaluation, we downgraded the evidence quality of primary outcomes from high to low or very low because of the high risk of bias due to unclear sequence generation and allocation concealment. Moreover, we observed very small sample sizes in several trials combined with higher levels of heterogeneity that showed significant inconsistency between trials.

\section{Strengths and weaknesses}

In the current NMA, evidence was integrated from both direct and indirect comparisons. The literature search

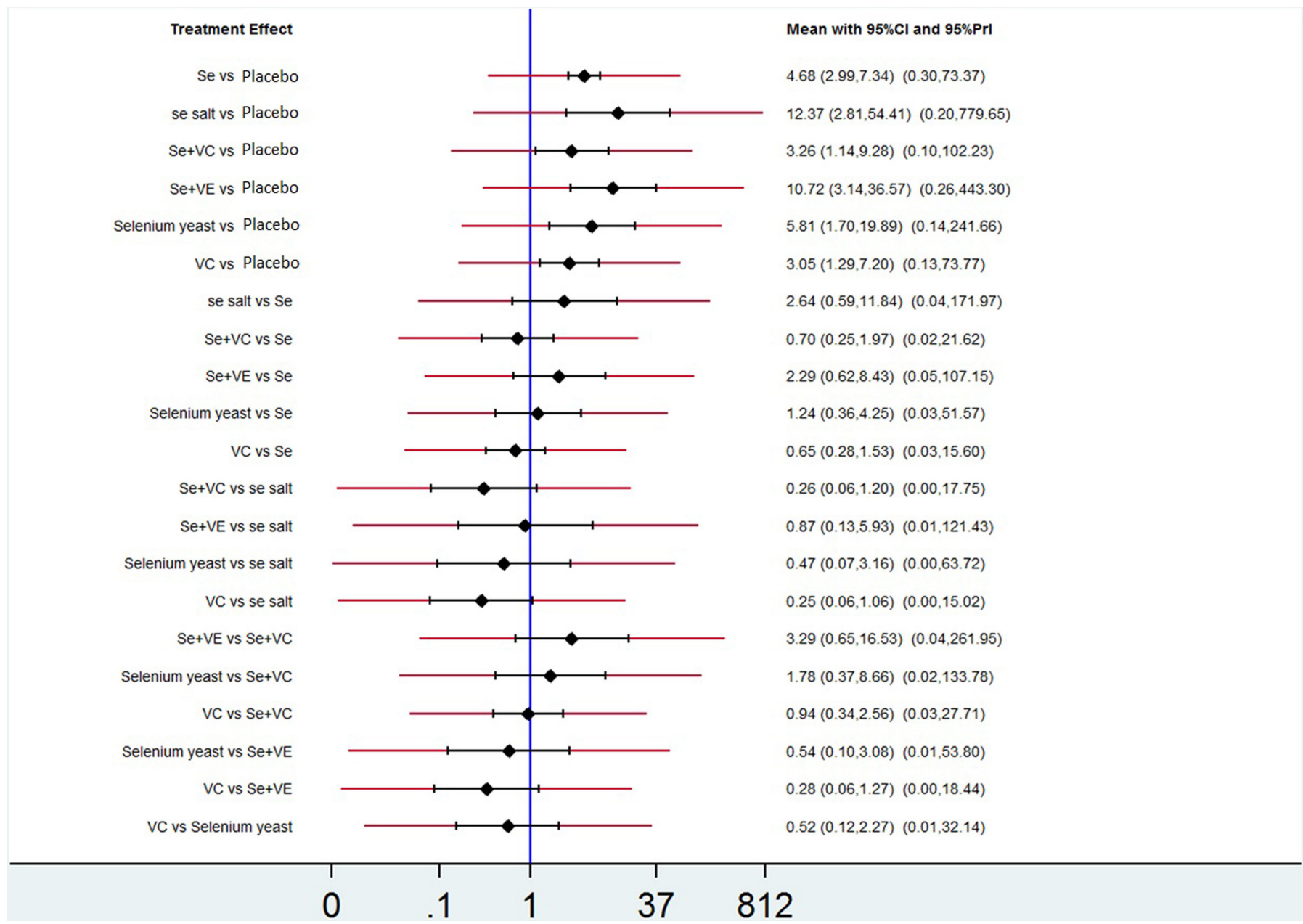

Figure 3 Network estimates of mean ORs, their 95\% Cls and 95\% prediction intervals (red extensions),

$\mathrm{Prl}$, prediction intervals; Se, sodium selenite; Se salt, selenium salt; Se+VC, the combination of sodium selenite with vitamin C; $\mathrm{Se}+\mathrm{VE}$, the combination of sodium selenite with vitamin E; Se yeast, selenium enriched yeast; VC, vitamin C. 


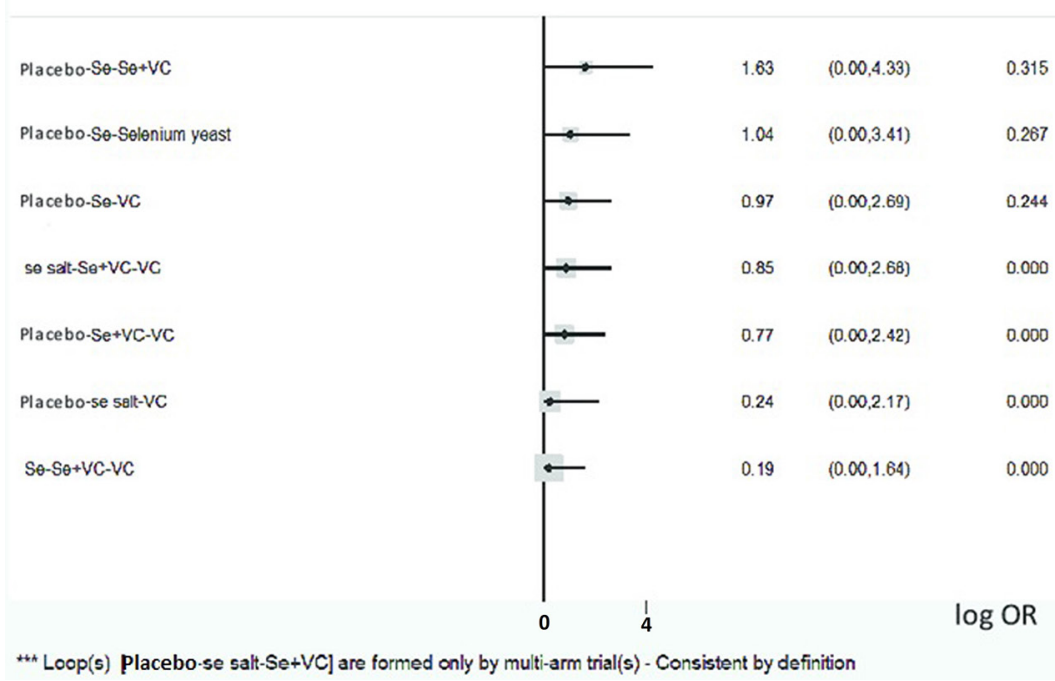

Figure 4 Consistency test in the network meta-analysis. The X-axis is $\log \mathrm{OR}$, and the vertical line is $\mathrm{O}$. IF is the absolute inconsistency factor, meaning the logarithm of the ratio of ORs of direct and indirect evidences for each comparison loop. The absolute IF values and Cls are truncated at zero indicate no significant difference of inconsistency. IF, inconsistency factor; Se, sodium selenite; Se salt, selenium salt; Se+VC, the combination of sodium selenite with vitamin C; Se yeast, selenium enriched yeast; VC, vitamin C.

strategy was extensive, and it was unlikely that relevant trials were missed. The selection of trials as well as the extraction of data and quality assessments were performed by two investigators to minimise bias and transcription errors. In this NMA, we applied the GRADE system to
NMAs based on the GRADE working group to rate the quality of the evidence.

Although the results are promising, this study has several limitations. First, the length of follow-up varied greatly, and varied from 6 to 36 months. However, follow-up
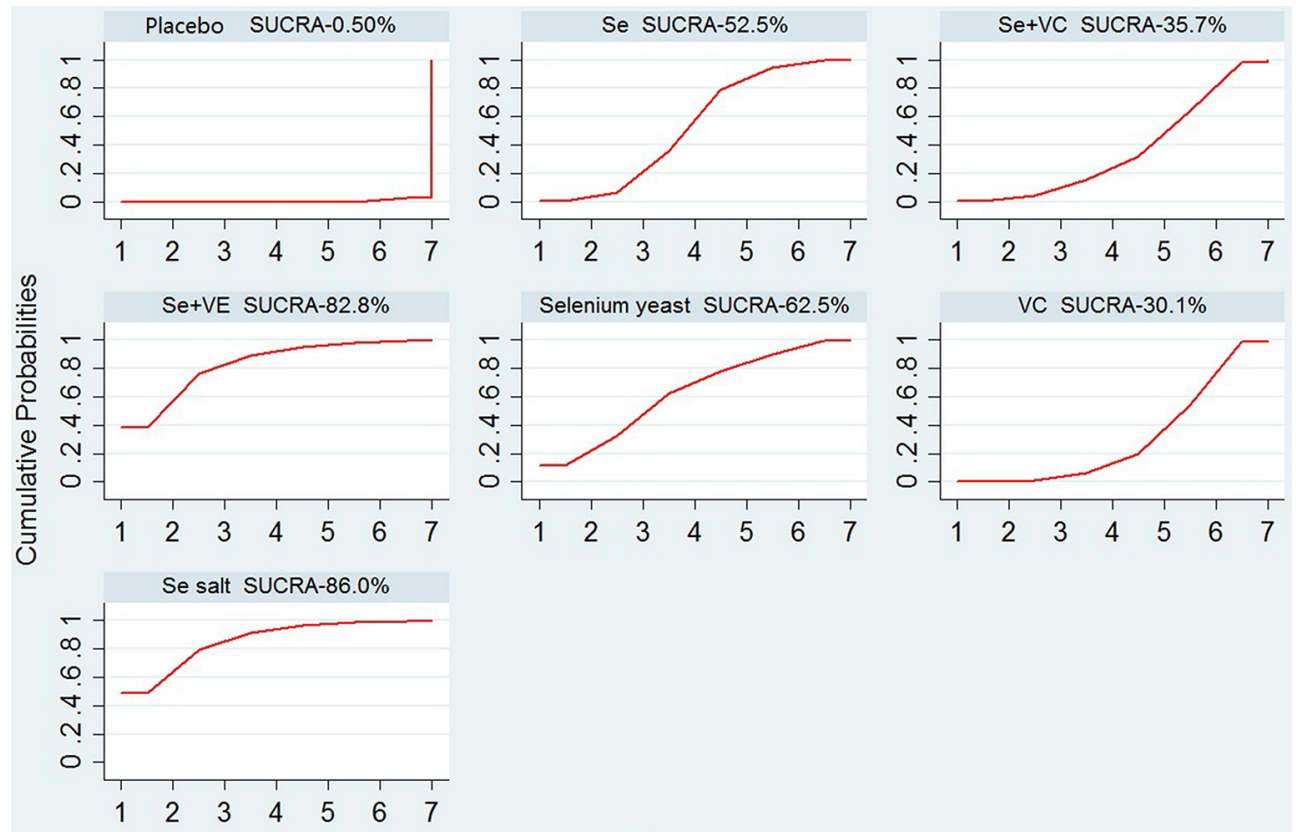

Graphs by Treatment

Rank

Figure 5 SUCRA for the cumulative probabilities. Se, sodium selenite; Se salt, selenium salt; Se+VC, the combination of sodium selenite with vitamin $\mathrm{C}$; Se+VE, the combination of sodium selenite with vitamin E; SUCRA, surface under cumulative ranking; VC, vitamin $\mathrm{C}$. 
period of most studies is concentrated in 12 months. Therefore, the data in our review were extracted to the nearest 12 months. Even so, the best beneficial duration of therapy period remains unclear for KBD. When compared with other RCTs in osteoarthritis, 36 months of therapy might be appropriate for detecting X-ray-related alterations of KBD. Second, the sample size of the RCTs included in our NMA was limited. Third, despite our extensive research, we were only able to include 15 RCTs in our NMA that were performed in China. Apart from China, both North Korea and Russia have a high KBD incidence, and it is likely that in our search, trials that were published in local journals may have been missed. Finally, in this study, the heterogeneity was relatively high that may be explained by a lack of allocation concealment, limited number of samples and alterations between selenium preparations. Similar as with heterogeneity between trials, inconsistency between direct and indirect comparisons was close to zero. Clinically relevant inconsistency cannot be ruled out; therefore, there is no indication that clinical characteristics of enrolled subjects or additional features of the trial confounded indirect comparisons.

\section{CONCLUSIONS}

\section{Implications for clinical practice}

Based on the current NMA, all types of Se supplementation were of higher efficiency compared with the placebo in treating KBD in children. Ranking on efficacy indicated that Se salt was highest, followed by $\mathrm{Se}+\mathrm{VE}$, Se enriched yeast, Se, Se+VC, VC and placebo/no treatment. Since the overall assessment quality was relatively low (or very low), the SUCRA values may be misleading and should be considered jointly with the GRADE confidence in the estimates for each comparison. Evidence quality is insufficient to draw a conclusion about what method of selenium supplementation is most effective. Se salt can be an economical and convenient strategy for controlling KBD in endemic areas. However, selenium overdose is toxic. Therefore, suitable dosages should be strictly controlled and content of selenium should be closely monitored to prevent detrimental health-related issues.

\section{Implications for research}

Since KBD among children has almost disappeared, it is highly unlikely that upcoming trials involve RCT to demonstrate the clinically relevant benefit of any selenium supplementation for children with KBD. Currently, no effective therapy exists to correct KBD-related cartilage damage in adults. Novel approaches, including gene therapy and tissue engineering, may become a potential treatment strategy that can be used for treating KBD-related cartilage damages.

Acknowledgements $\mathrm{Dr}$ Joseph H. Flaherty is especially acknowledged for editorial review and language assistance.
Contributors DX and YL conceived the review question, reviewed studies for inclusion, assessed the included studies, extracted data, completed the first draft and edited the review. JY and CZ analysed the data, did the literature search, advised and co-ordi-nated the review development, performed part of the writing and editing of the review, approved the final version of the review prior to submission, and is also a guarantor. YW, CD and LC contributed to the development of the review question, edited and provided intellectual contributions to the review.

Funding This research was funded by China National Science \& Technology Pillar Program (2007BA125B04).

Competing interests None declared.

Patient consent Parental/guardian consent obtained.

Provenance and peer review Not commissioned; externally peer reviewed.

Data sharing statement No additional data are available.

Open Access This is an Open Access article distributed in accordance with the Creative Commons Attribution Non Commercial (CC BY-NC 4.0) license, which permits others to distribute, remix, adapt, build upon this work non-commercially, and license their derivative works on different terms, provided the original work is properly cited and the use is non-commercial. See: http://creativecommons.org/ licenses/by-nc/4.0/

(c) Article author(s) (or their employer(s) unless otherwise stated in the text of the article) 2018. All rights reserved. No commercial use is permitted unless otherwise expressly granted.

\section{REFERENCES}

1. Mathieu F, Begaux F, Lan ZY, et al. Clinical manifestations of KashinBeck disease in Nyemo Valley, Tibet. Int Orthop 1997;21:151-6.

2. Sokoloff L. The history of Kashin-Beck disease. N Y State J Med 1989;89:343-51.

3. Allander E. Kashin-Beck disease. An analysis of research and public health activities based on a bibliography 1849-1992. Scand $J$ Rheumatol Suppl 1994;99:1-36.

4. P. R. C. Ministry of Health. The prevention and control status of Kaschin-Beck disease in 2011.. 2012 http://www.nhfpc.gov.cn/ htmlfiles/zwgkzt/ptjnj/year2012/index2012.html

5. Xiong G, Diagnostic XG. Diagnostic, clinical and radiological characteristics of Kashin-Beck disease in Shaanxi Province, PR China. Int Orthop 2001;25:147-50.

6. Peng A, Yang C, Rui H, et al. Study on the pathogenic factors of Kashin-Beck disease. J Toxicol Environ Health 1992;35:79-90.

7. Luo R, Liu G, Liu W, et al. Efficacy of celecoxib, meloxicam and paracetamol in elderly Kashin-Beck disease (KBD) patients. Int Orthop 2011;35:1409-14.

8. Yu FF, Xia CT, Fang H, et al. Evaluation of the therapeutic effect of treatment with intra-articular hyaluronic acid in knees for Kashin-Beck disease: a meta-analysis. Osteoarthritis Cartilage 2014;22:718-25.

9. Mathieu F, Suetens C, Begaux F, et al. Effects of physical therapy on patients with Kashin-Beck disease in Tibet. Int Orthop 2001;25:191-3.

10. Yue J, Yang M, Yi S, et al. Chondroitin sulfate and/or glucosamine hydrochloride for Kashin-Beck disease: a cluster-randomized, placebo-controlled study. Osteoarthritis Cartilage 2012;20:622-9.

11. Zhongmin $T$, Yang $L$, Zhou J, et al. Comparison of treatment results of arthroscopic knee debridement alone with a combination of arthroscopic debridement and drilling decompression in knee Kaschin-Beck disease (in Chinese). Chin J Endo 2009:371-4.

12. Liu FD, Wang ZL, Hinsenkamp M. Osteotomy at the knee for advanced cases of Kashin-Beck disease. Int Orthop 1998;22:87-91.

13. Guo X, Ma WJ, Zhang F, et al. Recent advances in the research of an endemic osteochondropathy in China: Kashin-Beck disease. Osteoarthritis Cartilage 2014;22:1774-83.

14. Zou K, Liu G, Wu T, et al. Selenium for preventing Kashin-Beck osteoarthropathy in children: a meta-analysis. Osteoarthritis Cartilage 2009;17:144-51.

15. Jirong $Y$, Huiyun $P$, Zhongzhe $Y$, et al. Sodium selenite for treatment of Kashin-Beck disease in children: a systematic review of randomised controlled trials. Osteoarthritis Cartilage 2012;20:605-13.

16. National Health and Family Planning Commission of the People's Republic of China. Diagnostic criteria of Kashin-Beck disease (GB16003-1995). 1995 (accessed 15 Dec 1995).

17. Liang S, Zhang F, Wang L, et al. The effect of the treatment of Kaschin Beck disease (in Chinese). Chin J Endo 1996;15:378-80. 
18. Higgins J, Green S. Cochrane handbook for systematic reviews of interventions (version 5.1.0). London, UK: The Cochrane Collaboration, 2011. http://www.cochrane-handbook.org

19. Puhan MA, Schünemann HJ, Murad MH, et al. A GRADE working group approach for rating the quality of treatment effect estimates from network meta-analysis. BMJ 2014;349:g5630.

20. Eckermann S, Coory M, Willan AR. Indirect comparison: relative risk fallacies and odds solution. J Clin Epidemiol 2009;62:1031-6.

21. Jackson D, Barrett JK, Rice S, et al. A design-by-treatment interaction model for network meta-analysis with random inconsistency effects. Stat Med 2014;33:3639-54.

22. Niu GH, Zhang BH, Song ZY, et al. An observation study on effect of oral sodium selenite for prevention and treatment of kashin-beck effect (in Chinese). Heilongjiang Med J 1981:15-17.

23. The Yongshou Scientific Survey Group of Kaschin-Beck Disease. Effect and mechanism of seleniumin the prevention and cure of 424 Kaschin-Beck's patients (in Chinese). Chin J Endemiol 1982:1:145-50.

24. Wang DS, Bs F, Sun QY, et al. Dynamic observation of sodium selenite and vitamin $E$ in the treatment of Kashin Beck disease (in Chinese). Chin J Endemiol 1983;2:204-7.

25. Cui ZJ, Lin BH, Jin CS, et al. An observation on effect of the treatment of Kaschin-Beck disease using Vitamin $\mathrm{C}$ or sodium selenite (in Chinese). End Dis Bull 1984;1:63.

26. Niu GH, Zhang BZ, Xz L, et al. Results of study of two years on the preventing and controlling Kashin-Beck's disease with selenium seen under X-rays and discussion of etiology (in Chinese). Chin J Endemiol 1984;3:199-201.

27. Guo LB, Lu Q, Tang HF, et al. An one year observation by X-ray on effect of the treatment of Kaschin-Beck disease using oral sodium selenite (in Chinese). J Chengde Univ Med Sci 1985:67-70.

28. Guo LB, Lu Q, Dong HQ, et al. One year of observation on effect of selenium enriched yeast for treatment of Kaschin Beck disease (in Chinese). Chin J Endemiol 1986;5:16-20.

29. Niu GH, Zhang BZ, Hou SF, et al. Study of two years on the preventing and controlling Kashin-Beck's disease with oral sodium selenite seen under X-rays (in Chinese). J Pract Endemio 1986;1:16-18.

30. Qx W. An observation by X-ray on effect of the prevention and treatment of Kaschin-Beck disease using oral sodium selenite (in Chinese). Chin J Endemiol 1986;5:210-20.

31. Deng JY. Effect of sodium selenite oral application on Kashin-Beck disease, a three years observation (in Chinese). Chin J Endemiol $1988 ; 7: 117-20$
32. Niu GH, Zhang BZ, Hou SF. Effect of semis-dosage selenium on controlling of Kashin-Beck disease (in Chinese). Chin J Endemiol 1990:99-100.

33. Zhou XK, Wang WL, Wang EQ, et al. The observation on effecto of selenium and vitamin $\mathrm{C}$ for treating Kaschin Beck disease (in Chinese). End Dis Bull 1991:100-3.

34. Moreno-Reyes R, Mathieu F, Boelaert M, et al. Selenium and iodine supplementation of rural Tibetan children affected by Kashin-Beck osteoarthropathy. Am J Clin Nutr 2003;78:137-44.

35. Chen Y, Huo JM, Wang ZL, et al. A comparative research on the treatment effect of Se supplement, Vit C supplement and cereals dryness on Kaschin -Beck disease (in Chinese). Chin J Endemiol 2003;18:343-6.

36. Cai LW, Zhang YL. An observation by X-ray on effect of selenium in the treatment of 40 Kaschin-Beck children (in Chinese). J Comm Med 2005;3:60-1.

37. Yao Y, Pei F, Kang P. Selenium, iodine, and the relation with KashinBeck disease. Nutrition 2011;27:1095-100.

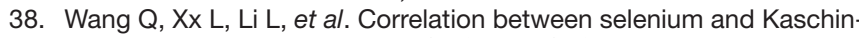
Beck disease: a meta-analysis (in Chinese). Chin J Evid Based Med 2013;13:1421-30.

39. Yu FF, Han J, Wang $X$, et al. Salt-Rich selenium for prevention and control children with kashin-beck disease: a meta-analysis of community-based trial. Biol Trace Elem Res 2016;170:25-32.

40. Guo X, Ding D, Wang Z, et al. A study on the reparative action of $\mathrm{X}$-ray lesions in metaphyses and distal end of bone in children's fingers with kashin-beck disease treated by se-fortified wheat (in Chinese). Chin J Ctrl Endem Dis 1990:269-72.

41. Chen D, Ren S, Lu W, et al. Effect of applying selenium fertilizer to improve soil and increase selenium level in food for prevention and treatment of Kaschin-Beck disease (in Chinese). J Env Sci 1993:5:299-309.

42. Gy X, Xy L, Cao XG. Analysis on monitoring data of Kaschin-Beck disease in Shannxi province during 19 years (in Chinese). Chin $J$ Contr End Dis 2009:442-6.

43. Ning $Y$, Wang $X$, Wang $S$, et al. Is it the appropriate time to stop applying selenium enriched salt in Kashin-Beck disease areas in China? Nutrients 2015;7:6195-212.

44. Moreno-Reyes R, Suetens C, Mathieu F, et al. Kashin-Beck osteoarthropathy in rural Tibet in relation to selenium and iodine status. N Engl J Med 1998;339:1112-20.

45. Sasaki S, Iwata $\mathrm{H}$, Ishiguro $\mathrm{N}$, et al. bone, and articular cartilage in rats. Nutrition 1994;10:538-43.

46. Goss AN, Sampson WJ, Townsend GC, et al. Effect of iodine deficiency on craniofacial growth in young common marmosets (Callithrix jacchus). J Craniofac Genet Dev Biol 1988;8:225-33. 